\title{
Time Evolution of the Wettability of Supported Graphene under Ambient Air Exposure
}

\author{
Adrianus I. Aria, ${ }^{\dagger}$ Piran R. Kidambi, ${ }^{\dagger, \S}$ Robert S. Weatherup, ${ }^{\dagger, \|}$ Long Xiao, ${ }^{\dagger}$ John A. Williams, ${ }^{\ddagger}$ \\ and Stephan Hofmann $*{ }^{\dagger}$ \\ ${ }^{\dagger}$ Division of Electrical Engineering and ${ }^{\star}$ Division of Mechanics, Materials and Design, Department of Engineering, University of \\ Cambridge, Cambridge, United Kingdom CB2 1PZ \\ ${ }^{\S}$ Department of Mechanical Engineering, Massachusetts Institute of Technology, Cambridge, Massachusetts 02139-4307, United \\ States \\ "Materials Sciences Division, Lawrence Berkeley National Laboratory, Berkeley, California 94720, United States
}

Supporting Information

ABSTRACT: The wettability of graphene is both fundamental and crucial for interfacing in most applications, but a detailed understanding of its time evolution remains elusive. Here we systematically investigate the wettability of metal-supported, chemical vapor deposited graphene films as a function of ambient air exposure time using water and various other test liquids with widely different surface tensions. The wettability of graphene is not constant, but varies with substrate interactions and air exposure time. The substrate interactions affect the initial graphene wettability, where, for instance, water contact angles of $\sim 85$ and $\sim 61^{\circ}$ were measured for $\mathrm{Ni}$ and $\mathrm{Cu}$ supported graphene, respectively, after just minutes of air exposure. Analysis of the surface free energy components indicates that the substrate interactions strongly influence the Lewis acid-base component of supported graphene, which is considerably weaker

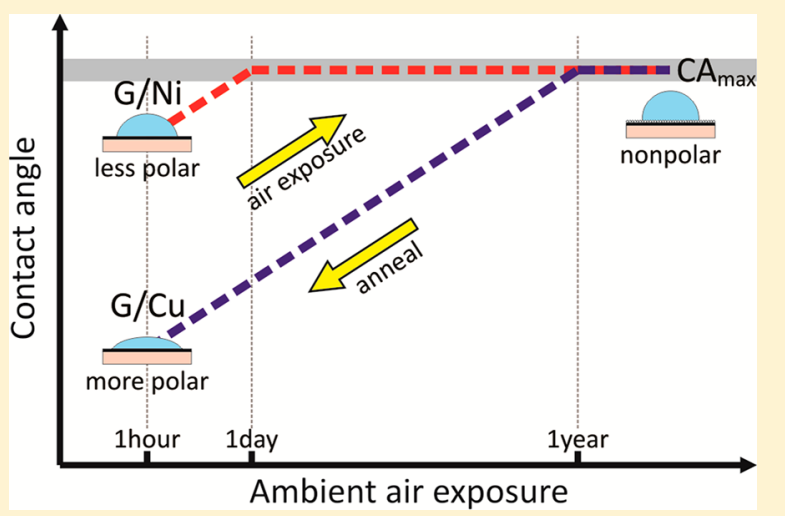
for $\mathrm{Ni}$ supported graphene than for $\mathrm{Cu}$ supported graphene, suggesting that the classical van der Waals interaction theory alone is insufficient to describe the wettability of graphene. For prolonged air exposure, the effect of physisorption of airborne contaminants becomes increasingly dominant, resulting in an increase of water contact angle that follows a universal linearlogarithmic relationship with exposure time, until saturating at a maximum value of $92-98^{\circ}$. The adsorbed contaminants render all supported graphene samples increasingly nonpolar, although their total surface free energy decreases only by $10-16 \%$ to about $37-41 \mathrm{~mJ} / \mathrm{m}^{2}$. Our finding shows that failure to account for the air exposure time may lead to widely different wettability values and contradicting arguments about the wetting transparency of graphene.

\section{INTRODUCTION}

Arguably the most challenging tasks in enabling technology based on graphene and other two-dimensional (2D) materials are their manufacturing and controlled interfacing. Given the significant progress in understanding the catalytic chemical vapor deposition (CVD) process, ${ }^{1-3}$ large-area "electronicgrade" graphene films can now routinely be produced, ${ }^{4,5}$ and the properties and device integration of these films can be explored. As these films are atomically thin, their properties are inevitably largely extrinsic, i.e. depend critically on support, conditions, and environment. Liquid wettability, quantified by the contact angle (CA), is a fundamental, widely used surface property whose importance permeates a wide variety of application areas, ranging from the electrochemical to biomedical. CA measurements for bulk or thin film materials can already be nontrivial, for instance due to surface reactions, interfacial interactions, roughness, or contamination effects, and the understanding of its microscopic origins remains incom- plete. $^{6,7}$ The determination and interpretation of wetting for nanomaterials, such as graphene, is highly complex and challenging, and the CA values so far reported for graphene films vary hugely with several completely contradictory reports in the literature. ${ }^{8-10}$ Hence, the development of a fundamental understanding of the origins of the wetting behavior of graphene and its evolution with time remains elusive. ${ }^{8-10}$ Graphene covered metal surfaces are a particularly interesting model system for a systematic study of wettability, since metalgraphene interactions have been studied in detail for the CVD process and graphene can be directly grown on catalytically active metal surfaces; i.e. the interfacing can experimentally be well controlled and no additional graphene transfer is required. On the basis of classical van der Waals interaction theory,

Received: October 26, 2015

Revised: January 7, 2016

Published: January 7, 2016 
recent literature highlights that the water CA is determined by the water-graphene as well as water-substrate interactions, indicating various degrees of wetting transparency. ${ }^{8-11}$ However, given the complexity of the system, there is a clear need for more experimental wetting data for graphene and other $2 \mathrm{D}$ materials.

Here, we systematically investigate the wettability of metalsupported CVD graphene films as a function of ambient air exposure time using water and various other test liquids. We focus on continuous, polycrystalline monolayer graphene on $\mathrm{Cu}$ and $\mathrm{Ni}$ supports, as these are the most widely used CVD process catalysts and are archetypes for weakly and strongly interacting metals, respectively. We demonstrate herein that the initial wettability of supported graphene samples is high, where perfect wetting is exhibited by low surface tension liquids, such as heptane, paraffin, and bromonaphthalene, and a relatively low CA is observed for higher surface tension liquids, such as formamide, glycerol, and water. We show that the underlying substrate does affect the initial wettability of graphene where, for instance, after minutes of air exposure a water CA (WCA) value of $\sim 85^{\circ}$ was measured for $\mathrm{Ni}$ supported graphene, compared to $\sim 61^{\circ}$ for $\mathrm{Cu}$ supported graphene. Our analysis of the surface free energy components using various well-known fitting models indicates that supported graphene has a nonnegligible initial polarity with a total initial surface free energy of about $42-48 \mathrm{~mJ} / \mathrm{m}^{2}$. Furthermore, the initial Lewis acidbase component of $\mathrm{Cu}$ supported graphene is considerably stronger than that on $\mathrm{Ni}$ support. This suggests that the classical van der Waals interaction theory alone is not sufficient to describe the wettability of graphene. Furthermore, we show that in the measured time frame of over a year of ambient air exposure the WCA of supported graphene increases logarithmically with time and eventually saturates at a value of $92-98^{\circ}$. While our data highlight distinctly different long-term oxidation behaviors of the metals underneath the graphene, they also indicate that the dominating cause for the long-term wettability evolution observed here is that of physisorption of airborne contaminants, in line with previous literature on the water wettability of graphite, ${ }^{12,13}$ which has been recently expanded to supported graphene. ${ }^{14,15}$ The adsorbed contaminants, mainly in the form of hydrocarbons, render all supported graphene samples increasingly nonpolar, such that they gradually lose their wettability, while their total surface free energy only decreases slightly to about $37-41 \mathrm{~mJ} / \mathrm{m}^{2}$. Changes in surface polarity and energy may lead to changes in other properties of graphene, and this implies that the performance of graphene devices, such as for electronics, photonics, sensors, heat exchangers, coatings, and membranes, may also be susceptible to degradation over time, especially if they are exposed to air during storage and usage. The findings presented herein allow us to rationalize and develop a scientific understanding of the widely different graphene CA values in previous literature. Our measurements also clearly establish a basis for further detailed experimental studies as well as offer insights for theoretical studies of the wettability of graphene and related $2 \mathrm{D}$ materials, ultimately to the benefit of their many future application areas.

\section{MATERIALS AND METHODS}

All supported graphene samples were grown by chemical vapor deposition (CVD) on various metal catalysts in both cold-wall and hot-wall CVD reactors as described in detail elsewhere. ${ }^{3,16-18}$ Two types of CVD graphene were used in this study: CVD graphene grown on copper $(\mathrm{G} / \mathrm{Cu})$ and $\mathrm{CVD}$ graphene grown on nickel (G/Ni). Highly oriented pyrolytic graphite (Agar Scientific, $3.5 \pm 1.5$ mosaic spread) that had been mechanically cleaved was used as a control. The $\mathrm{G} / \mathrm{Cu}$ samples were grown on polycrystalline $\mathrm{Cu}$ foils (Alfa Aesar, 25 $\mu \mathrm{m}$ thick, $99.999 \%$ purity) using $\mathrm{C}_{6} \mathrm{H}_{6}$ vapor precursor at a partial pressure of $10^{-3} \mathrm{mbar}$ and a temperature of $\sim 900^{\circ} \mathrm{C}$, 3,17 or using $\mathrm{H}_{2}$ diluted $\mathrm{CH}_{4}(0.1 \%$ in $\mathrm{Ar})$ precursor at a partial pressure of $10^{-3} \mathrm{mbar}$ and a temperature of $\sim 1050^{\circ} \mathrm{C}$. The G/ $\mathrm{Ni}$ samples were grown on polycrystalline Ni foils (Alfa Aesar, $25 \mu \mathrm{m}$ thick, $99.99 \%$ purity) using $\mathrm{C}_{6} \mathrm{H}_{6}$ precursor at a partial pressure of $10^{-5} \mathrm{mbar}$ and a temperature of $\sim 600{ }^{\circ} \mathrm{C}$. $^{18,19}$ These CVD methods result in a predominantly monolayer graphene with a complete coverage of the growth substrates by the graphene layer (see Supporting Information, Figure S1). Bare (graphene-free) $\mathrm{Cu}$ and $\mathrm{Ni}$ foils from the same batch were used as control samples. These control samples were annealed according to the above-mentioned methods, but without the exposure to hydrocarbons.

Following growth, all samples were exposed to ambient air while being stored in unsealed polystyrene sample boxes. This allows all samples, during the storage period, to be exposed to ambient air at room pressure, temperature, and humidity, while preventing the excessive buildup of dust and dirt. Here, the ambient air exposure time is determined from the time at which these graphene samples were taken out from the reactor, with uncertainty within $\pm 10 \%$ of the nominal time. To ensure such a low time uncertainty is consistently achieved, all measurements on graphene samples were performed after tens of minutes of air exposure to account for the sample handling and mounting time. For the reannealed graphene samples, the ambient air exposure time is also determined from the time at which these graphene samples were taken out from the annealing reactor. The reannealed graphene samples were produced by annealing old graphene samples in $\mathrm{Ar}$ at a total pressure of less than $10^{-6}$ mbar and a temperature of $250{ }^{\circ} \mathrm{C}$ for $1 \mathrm{~h}$. For HOPG, the ambient air exposure time is determined from the time at which it was mechanically cleaved. To obtain measurements within a few minutes after cleaving, the HOPG samples were premounted on the goniometer prior to cleaving.

The wettability of each graphene samples was determined from their liquid contact angle (CA) measured by a custommade contact angle goniometer using the sessile drop technique as described in detail elsewhere. ${ }^{20,21}$ Water contact angle measurement was performed using freshly prepared, i.e. less than $1 \mathrm{~h}$ old, high-purity deionized water with an average resistivity of $18.2 \mathrm{M} \Omega \mathrm{cm}$ (Millipore, Milli-Q). For surface energy measurements, seven other test liquids were also used, including heptane (Fisher Scientific, 99\%), paraffin (Fisher Scientific, extra pure grade), bromonaphthalene (Fisher Scientific, 96\%), diiodomethane (Fisher Scientific, 99+\% stabilized), ethylene glycol (Fisher Scientific, 99.8\% anhydrous), formamide (Acros Organics, 99.5\%), and glycerol (Acros Organics, 99+\% extra pure). A liquid droplet of 3-5 $\mu \mathrm{L}$ was carefully dispensed onto each sample using a 23 gauge flat tip needle at a rate of $\sim 10 \mu \mathrm{L} / \mathrm{min}$ at standard room temperature and pressure. The captured liquid droplet images were then processed with LBADSA software to obtain $C A,{ }^{22}$ with measurement uncertainty of $\pm 3^{\circ}$. Note that, in this current study, all wettability measurements are represented by Young's CA that takes into account the topographical inhomogeneity of the samples (see Supporting Information, section 1 and Figures S1 and S2). Graphene surface free energies are calculated by fitting the CA data to three commonly used models: the 
Zisman model, ${ }^{23}$ the adjusted van Oss-Chaudhury-Good (aOCG) model, ${ }^{24}$ which is essentially the van OssChaudhury-Good model but with adjusted fitting parameters, $^{25}$ and the Chang-Chen (CC) model. ${ }^{26,27}$ Details and justification of these models are described in the Supporting Information, section 4 .

Surface characterization of graphene and bare metal samples was performed using X-ray photoelectron spectroscopy (XPS; Thermo Scientific, ESCALAB 250Xi) at an operating pressure of less than $10^{-10}$ mbar. A monochromated $\mathrm{Al} \mathrm{K} \alpha$ with a photon energy of $1486.6 \mathrm{eV}$ was used as the X-ray source. The emitted photoelectrons were collected by a hemispherical energy analyzer with a spectral resolution of $\pm 0.1 \mathrm{eV}$. All spectra were acquired using a spot size of $\sim 200 \mu \mathrm{m}$.

\section{RESULTS}

Figure 1 shows contact angle goniometry images of static sessile water drops on monolayer graphene films grown on

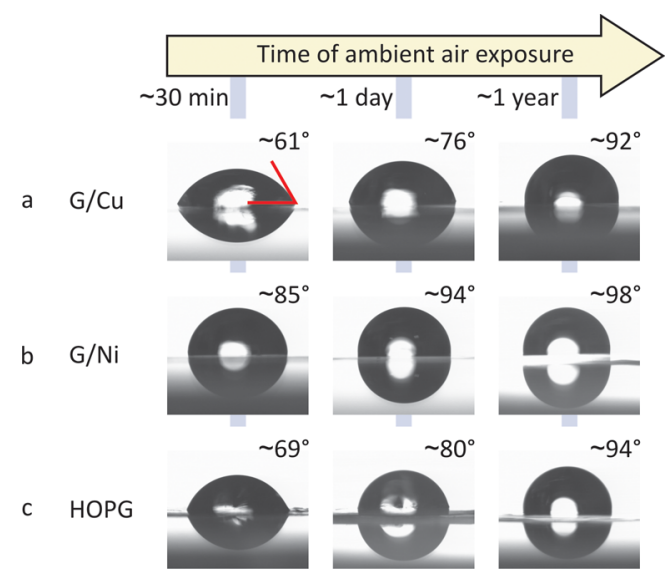

Figure 1. Contact angle goniometry images of static sessile water drops on the surface of $\mathrm{G} / \mathrm{Cu}(\mathrm{a}), \mathrm{G} / \mathrm{Ni}(\mathrm{b})$, and HOPG (c) that have been exposed to ambient air for $\sim 30 \mathrm{~min}, 1$ day, and 1 year. For $\mathrm{G} / \mathrm{Cu}$ and $\mathrm{G} / \mathrm{Ni}$, the ambient air exposure time starts at the time at which the samples are taken out of the reactor, whereas for HOPG it starts at the time at which it is mechanically cleaved.

polycrystalline $\mathrm{Cu}$ and $\mathrm{Ni}$ as a function of the sample's ambient air exposure time $t$ prior to the measurement. The change of the measured water contact angles (WCA) with $t$ is plotted in Figure $2 \mathrm{a}$, together with reference WCA values measured for graphite (HOPG) and bare metal substrates as well as reference apparent WCA values from previous literature. $t$ is thereby given with respect to the moment at which the samples were taken out of the graphene growth reactor or, for HOPG, to the moment when it was mechanically cleaved. For the shortest implemented ambient air exposure of $t=30 \mathrm{~min}$, the WCA for graphene on $\mathrm{Cu}(\mathrm{G} / \mathrm{Cu})$ is $\sim 61^{\circ}$, whereas graphene on $\mathrm{Ni}(\mathrm{G} /$ $\mathrm{Ni}$ ) is more hydrophobic with a WCA of $\sim 85^{\circ}$ (Figure 1a,b). Figure 1 and Figure 2a clearly show that for all graphene samples the WCA monotonically increases with $t$ at a rate that follows a simple linear-logarithmic relationship of WCA $\propto$ $\log (t)$. Eventually the WCA for all samples plateaus at $92-98^{\circ}$, indicated as $\mathrm{WCA}_{\max }$ in Figure $2 \mathrm{a}$. $\mathrm{WCA}_{\max }$ is most quickly reached after $t=1$ day for $\mathrm{G} / \mathrm{Ni}$, due to the higher initial WCA value. The behavior of HOPG is found to closely resemble that of $\mathrm{G} / \mathrm{Cu}$, with $\mathrm{WCA}_{\max }$ reached after $t=8-9$ months.

Figure $2 \mathrm{~b}$ compares the time-dependent wetting behavior of the graphene samples to that of the HOPG reference. The indicated reference line represents what has been previously referred to as "nonwetting transparency", where the wettability of supported graphene is the same as that of bulk graphite. ${ }^{10}$ Figure $2 \mathrm{~b}$ shows that the slope of the linear regression between $\mathrm{G} / \mathrm{Cu}$ and HOPG is almost unity, which means that the graphene on $\mathrm{Cu}$ essentially behaves as the HOPG surface. In contrast, the behavior of $\mathrm{G} / \mathrm{Ni}$ is significantly different. Hence there is no general "nonwetting transparency" for graphene. Figure $2 \mathrm{c}$ compares the graphene samples to the bare $\mathrm{Cu}$ and $\mathrm{Ni}$ reference substrates, which also have been pretreated in the same growth reactor. The WCA of bare $\mathrm{Cu}$ and Ni substrates is consistently lower compared to $\mathrm{G} / \mathrm{Cu}$ and $\mathrm{G} / \mathrm{Ni}$ (see also Supporting Information, Figure S3), and its increase with $t$ is steeper than a simple linear-logarithmic relationship especially within the first few hours of ambient air exposure. Figure $2 c$ indicates a limited correspondence between the wettability evolution of $\mathrm{G} / \mathrm{Cu}$ and bare $\mathrm{Cu}$, and an even less correlative relationship between the WCA of G/Ni and that of $\mathrm{Ni}$. The reference line indicated in Figure $2 \mathrm{c}$ represents what has been previously referred to as "complete wetting transparency", where the wettability of supported graphene is the same as that of its underlying substrate. If the data in Figure $2 \mathrm{c}$ are extrapolated toward $t<30 \mathrm{~min}$, the difference in WCA between graphene samples and the corresponding bare metal substrates becomes larger as $t$ decreases. This implies that the less the graphene is exposed to ambient air, the more it deviates from the "complete wetting transparency" hypothesis. Therefore, no general "wetting transparency" can be claimed, as our data clearly show that the graphene covered metal samples behave differently from the corresponding bare metal samples.

Figure 3 shows XPS analysis of the supported graphene samples with reference to HOPG and the respective bare metal substrates. We have previously studied in detail the XPS core level and Auger signatures of $\mathrm{Cu}$ and $\mathrm{Ni}$ catalyzed graphene CVD. ${ }^{3,19,28,29}$ For G/Cu we have thereby shown that the $\mathrm{C} 1 \mathrm{~s}$ signature shifts to a lower binding energy (BE) of $\sim 284.4 \mathrm{eV}$ after air exposure, due to immediate oxygen intercalation and subsequent oxidation of the $\mathrm{Cu}$ surface. ${ }^{3,28}$ This is consistent with the post-air-exposure $\mathrm{C} 1 \mathrm{~s}$ peak position of $\mathrm{G} / \mathrm{Cu}$ we see here in Figure 3a. Upon a prolonged exposure to ambient air, this peak is broadened toward higher $\mathrm{BE}$ which is consistent with the adsorption of atmospheric contaminants, which are mainly attributed to hydrocarbons (see also Supporting Information, Figures S7 and S8). ${ }^{30-34}$ Figure $3 \mathrm{~b}$ shows the corresponding $\mathrm{Cu}$ LMM Auger signatures of $\mathrm{G} / \mathrm{Cu}$ and the bare $\mathrm{Cu}$ reference. Here we show the Auger signature, as it is more sensitive to changes in the oxidation state of $\mathrm{Cu}$ than the $\mathrm{Cu} 2 \mathrm{p}_{3 / 2}$ core level signature (see Supporting Information, Figure S6). The $\mathrm{Cu}$ Auger fingerprint of $\mathrm{G} / \mathrm{Cu}$ in Figure $3 \mathrm{~b}$ shows that the $\mathrm{Cu}$ clearly increasingly oxidizes underneath the graphene layer. This $\mathrm{Cu}$ oxidation is also optically visible as a homogeneous color change (see Supporting Information, Figure S5). ${ }^{3}$ Further, the Cu LMM spectrum of the 1 year old bare $\mathrm{Cu}$ substrate exhibits features associated with the formation of $\mathrm{CuO}$ and $\mathrm{Cu}_{2} \mathrm{O}$, which could also be observed in the corresponding $\mathrm{Cu} 2 \mathrm{p}$ and $\mathrm{O} 1 \mathrm{~s}$ spectra (see Supporting Information, Figures S6-S8). ${ }^{35,36}$ This implies a different oxidation behavior of graphene-covered and bare $\mathrm{Cu}$, which has to be considered (as discussed below) when comparing the wetting behaviors and when surface energies are extrapolated. ${ }^{37}$

The oxidation behavior of graphene-covered $\mathrm{Ni}$ is distinctly different. We have previously shown that a C 1s signature peak centered at $\sim 284.4 \mathrm{eV}$ corresponds to rotated (nonepitaxial) 

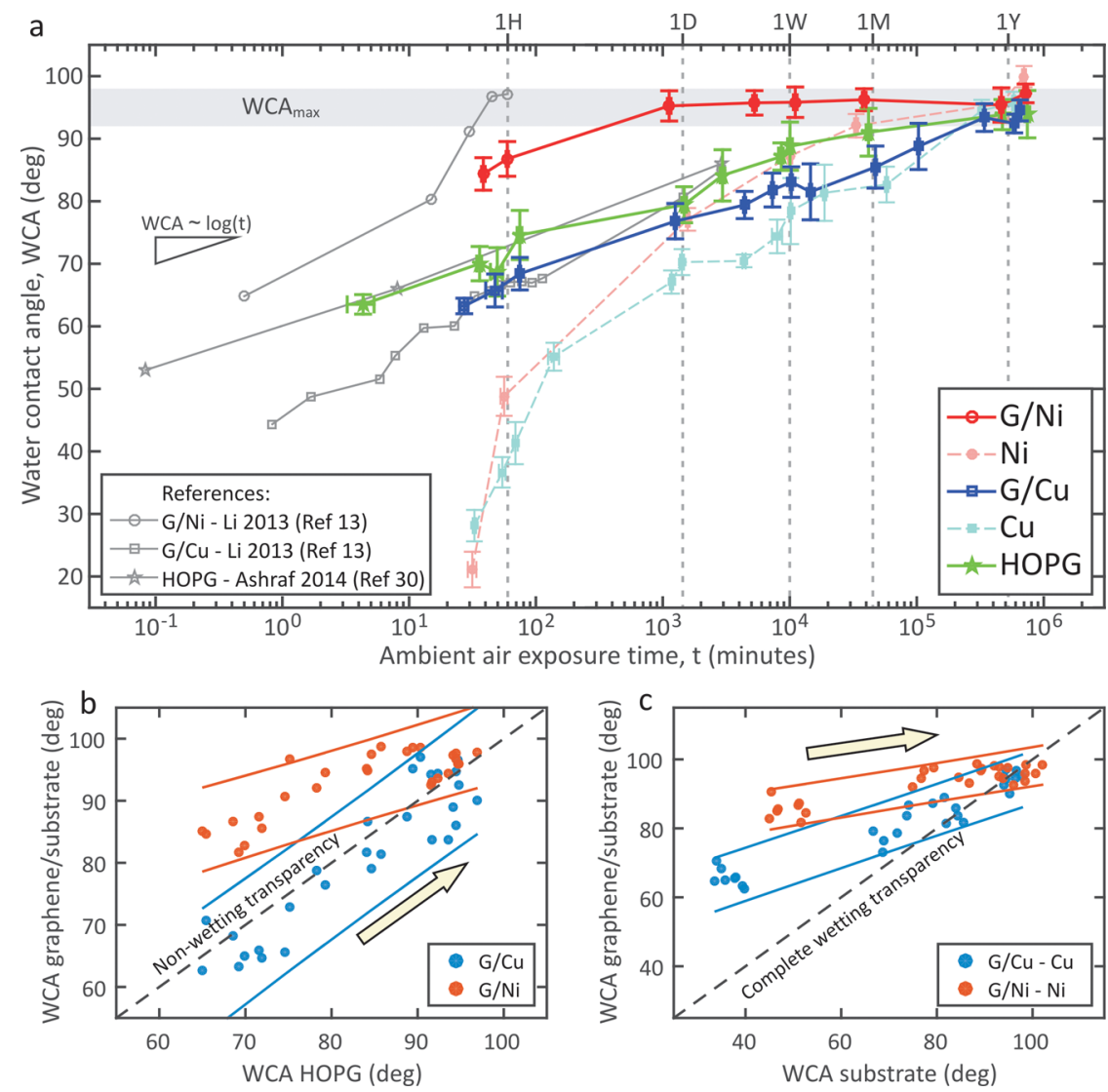

Figure 2. (a) Plot of graphene water contact angle (WCA) as a function of ambient air exposure time $(t)$. For comparison, plot of WCA of HOPG and the corresponding bare metal reference substrates is also included. The rate of increase of WCA follows a simple linear-logarithmic relationship of WCA $\propto \log (t)$, until it reaches a maximum value $\left(\mathrm{WCA}_{\max }\right)$. Error bars indicate standard deviation of measurements. (b) Plot of WCA of G/Cu and $\mathrm{G} / \mathrm{Ni}$ versus WCA of HOPG at corresponding ambient air exposure time points. The dashed reference line of WCA graphene $/$ substrate $=$ WCA HOPG represents the nonwetting transparency argument, which is mildly satisfied by G/Cu. (c) Plot of WCA of G/Cu and G/Ni versus WCA of corresponding bare metal substrate at corresponding ambient air exposure time points. The dashed reference line of WCA graphene/substrate $=$ WCA substrate represents the complete wetting transparency argument, which is not satisfied by both G/Cu and G/Ni. In (b) and (c), the increase in ambient air exposure time is indicated by the direction pointed by the yellow arrows, the solid lines indicate $95 \%$ prediction interval, and the measurement uncertainty of $\pm 3^{\circ}$ is represented by the size of each marker.

graphene on $\mathrm{Ni}$ which is typically observed for polycrystalline $\mathrm{Ni}$ foils, growth temperatures of $>500{ }^{\circ} \mathrm{C}$, and/or higher hydrocarbon exposure pressures. ${ }^{29,38}$ This is again consistent with the $\mathrm{C} 1$ s peak position we observe for $\mathrm{G} / \mathrm{Ni}$ in Figure 3a. Further, for prolonged exposure to ambient air, this $\mathrm{C}$ 1s peak again broadens toward higher $\mathrm{BE}$, which is consistent with hydrocarbon adsorption. Unlike $\mathrm{G} / \mathrm{Cu}$, however, the graphenecovered $\mathrm{Ni}$ does not oxidize even after $t=1$ year as highlighted in Figure 3c. ${ }^{39,40}$ We attribute this significant difference in oxidation behavior to the stronger interaction of graphene with $\mathrm{Ni}$ than with $\mathrm{Cu}^{39}$ The bare Ni reference shows in comparison clear oxidation features in the Ni $2 p$ core level signature (Figure $3 c$, see also Supporting Information, Figure S8). ${ }^{41}$ Hence, the oxidation behavior in ambient air is different for all samples.

Figure $4 \mathrm{a}$ highlights the effect of sample annealing on the wetting behavior and measured WCA. Samples that have been air-exposed for a long time, more than 100 days, and reached $\mathrm{WCA}_{\max }$ were reloaded into the growth reactor and annealed in Ar at $250{ }^{\circ} \mathrm{C}$ for $1 \mathrm{~h}$. Figure 4 a shows that the WCA of $\mathrm{G} / \mathrm{Cu}$ and $\mathrm{G} / \mathrm{Ni}$ samples immediately after this annealing decreased to $\sim 70$ and $\sim 80^{\circ}$, respectively, with the WCA then showing a linear-logarithmic increase with $t$ again. The annealed $\mathrm{G} / \mathrm{Ni}$ reaches $\mathrm{WCA}_{\max }$ again within $t=3$ days. On the other hand, the annealed $\mathrm{G} / \mathrm{Cu}$ reaches a WCA of $\sim 88^{\circ}$ for $t=10$ days after annealing. As discussed below, this is consistent with the wetting behavior being dominated by adsorbents.

While Figure 1 and Figure 2 focused on water, Figure $4 b$ summarizes our systematic investigation of the wetting behavior for a range of other test liquids with widely different surface tensions. For all samples and liquids probed, the contact angle (CA) shows a monotonic increase with $t$. G/Cu and HOPG exhibit a perfect wetting $\left(\mathrm{CA}=0^{\circ}\right)$ by low surface tension liquids (heptane, paraffin, and bromonaphthalene) for $t=1 \mathrm{~h}$. Similarly, these liquids, with the exception of bromonaphthalene, also perfectly wet $\mathrm{G} / \mathrm{Ni}$ at $t=1 \mathrm{~h}$. For $t=1$ year, the CAs of paraffin and bromonaphthalene on all graphene and HOPG samples increased to $6-12^{\circ}$ and $17-23^{\circ}$, respectively, while that of heptane remained $0^{\circ}$. For liquids with higher surface tension (diiodomethane, ethylene glycol, formamide, and glycerol), the increase in CA with $t$ is clearly seen for $\mathrm{G} / \mathrm{Cu}$ and HOPG. For instance, the average CAs of glycerol and formamide on $\mathrm{G} / \mathrm{Cu}$ are about 34 and $17^{\circ}$ higher at $t=1$ year, respectively, than at $t=1 \mathrm{~h}$. Similarly, the average CAs of diiodomethane and ethylene glycol on HOPG are about 23 and $18^{\circ}$ higher at $t=1$ year, respectively, than at $t=1 \mathrm{~h}$. On the other hand, the increase in CA with $t$ for $\mathrm{G} / \mathrm{Ni}$ is less obvious. For instance, the average CAs of diiodomethane and ethylene glycol on $\mathrm{G} / \mathrm{Ni}$ for $t=1$ year are only about 13 and $12^{\circ}$ higher, 

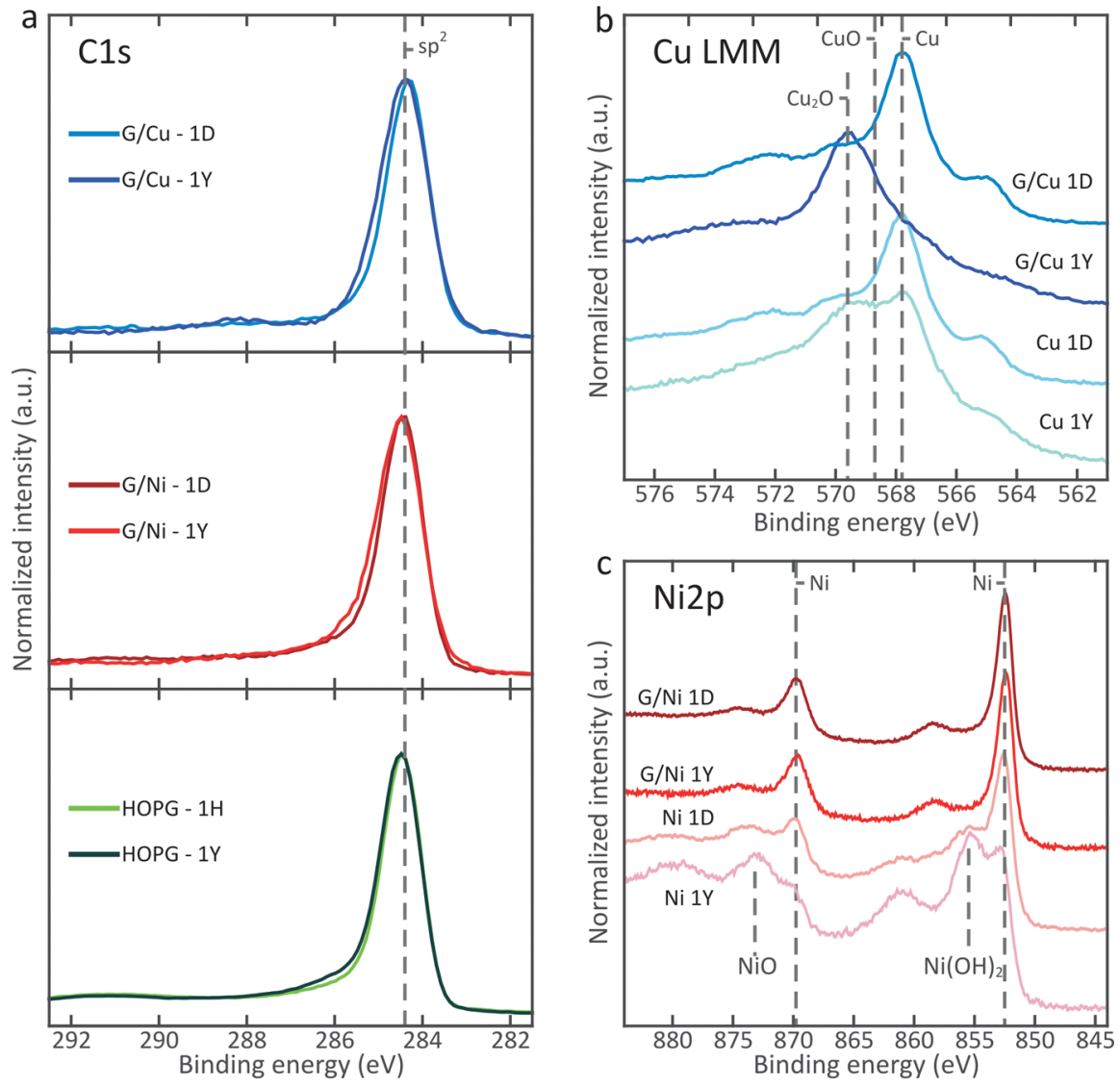

Figure 3. (a) XPS C 1s spectra of G/Cu, G/Ni, and HOPG measured at different ambient air exposure time points. For G/Cu and G/Ni, the spectra are measured from samples with $t=1$ day and $t=1$ year. For HOPG, the spectra are measured from samples with $t=1 \mathrm{~h}$ and $t=1$ year. Peak associated with $\mathrm{sp}^{2}$ carbon hybridization is found at $\sim 284.4 \mathrm{eV}$. Upon a prolonged exposure to ambient air, this peak is broadened toward higher $\mathrm{BE}$, which may indicate the buildup of adventitious carbon contamination. (b) XPS Cu LMM spectra of G/Cu and bare Cu substrate measured from samples with $t=1$ day and $t=1$ year. Peaks associated with metallic $\mathrm{Cu}, \mathrm{CuO}$, and $\mathrm{Cu}_{2} \mathrm{O}$ are found at 567.8, 568.7, and $569.6 \mathrm{eV}$, respectively. (c) XPS Ni 2p spectra of $\mathrm{G} / \mathrm{Ni}$ and bare Ni substrate measured from samples with $t=1$ day and $t=1$ year. Peaks at $\sim 852.5$ and $\sim 869.9 \mathrm{eV}$ are associated with metallic $\mathrm{Ni}\left(\mathrm{Ni} 2 \mathrm{p}_{3 / 2}\right.$ and $\mathrm{Ni} 2 \mathrm{p}_{1 / 2}$ core levels, respectively), and peaks at $\sim 855.1$ and $\sim 873 \mathrm{eV}$ are associated with the presence of $\mathrm{Ni}(\mathrm{OH})_{2}$ and $\mathrm{NiO}$, respectively. All spectra are collected with a spectral resolution of $\pm 0.1 \mathrm{eV}$.

respectively, than for $t=1 \mathrm{~h}$. We used the obtained CA data from various test liquids to calculate the Zisman critical surface energy $\left(\gamma_{\mathrm{C}}\right)$. Figure $4 \mathrm{c}$ shows that $\gamma_{\mathrm{C}}$ of graphene and HOPG samples for $t=1 \mathrm{~h}$ is found to be $41-42 \mathrm{~mJ} / \mathrm{m}^{2}$, whereas slightly lower values of $37-38 \mathrm{~mJ} / \mathrm{m}^{2}$ are obtained for $t=1$ year. Since the obtained $\gamma_{C}$ is not the actual surface free energy of graphene, it is used herein to determine the suitability of the test liquids. Based on this, heptane and paraffin, both of which have a surface tension lower than the lowest $\gamma_{\mathrm{C}}$ of the graphene samples (see also Supporting Information Figure S9), are unsuitable to determine the surface free energy of supported graphene.

\section{DISCUSSION}

Our XPS data highlight that the oxidation behavior in ambient air is different for all samples and the adsorbent coverage, in particular hydrocarbons, increases with increasing $t$. We have chosen $\mathrm{G} / \mathrm{Cu}$ and $\mathrm{G} / \mathrm{Ni}$ as model systems that exhibit weak and strong graphene-metal interactions, respectively, which results here in the distinctively different oxidation behavior of the metal substrate underneath the graphene. ${ }^{39}$ This in turn can affect the time-dependent wettability behavior and result in misleading "direct" comparisons to metal reference substrates. It should be noted that previous literature widely assumes that the underlying substrate of supported graphene remains metallic, such that its WCA remains at $0^{\circ}, 42$ as it is exposed to ambient air. ${ }^{10,14}$ Here, we show a much greater complexity, where the long-term oxidation behaviors, along with topographical inhomogeneities (see also Supporting Information, section 1, Figures S1 and S2), are found to be different for each sample. However, our data show that although the $\mathrm{Ni}$ underneath the graphene remains metallic even after $t=1$ year, the wetting behavior of $\mathrm{G} / \mathrm{Ni}$ clearly changes with $t$. Furthermore, we show that the contact angle can be "reset" by annealing the samples at $250{ }^{\circ} \mathrm{C}$ (Figure $4 \mathrm{a}$ ). For $\mathrm{G} / \mathrm{Cu}$, the data strongly suggest that oxygen intercalation and $\mathrm{Cu}$ oxidation occur underneath the graphene, which leads to a decoupling of the graphene (and accompanying loss of charge transfer from the $\mathrm{Cu}$ substrate). We have shown previously that this can be reversed and the graphene coupled to the $\mathrm{Cu}$ again by annealing up to $700{ }^{\circ} \mathrm{C} .{ }^{3}$ Here, we anneal only up to $250^{\circ} \mathrm{C}$, which is not sufficient to reverse the decoupling effect. Yet, the annealing clearly changes the contact angles for $\mathrm{G} / \mathrm{Cu}$ samples, which indicates that the dominating cause for the observed wetting behavior here is that of physisorption of airborne contaminants. ${ }^{14,15}$ However, our data highlight that oxidation effects and changes to the underlying substrates do clearly 

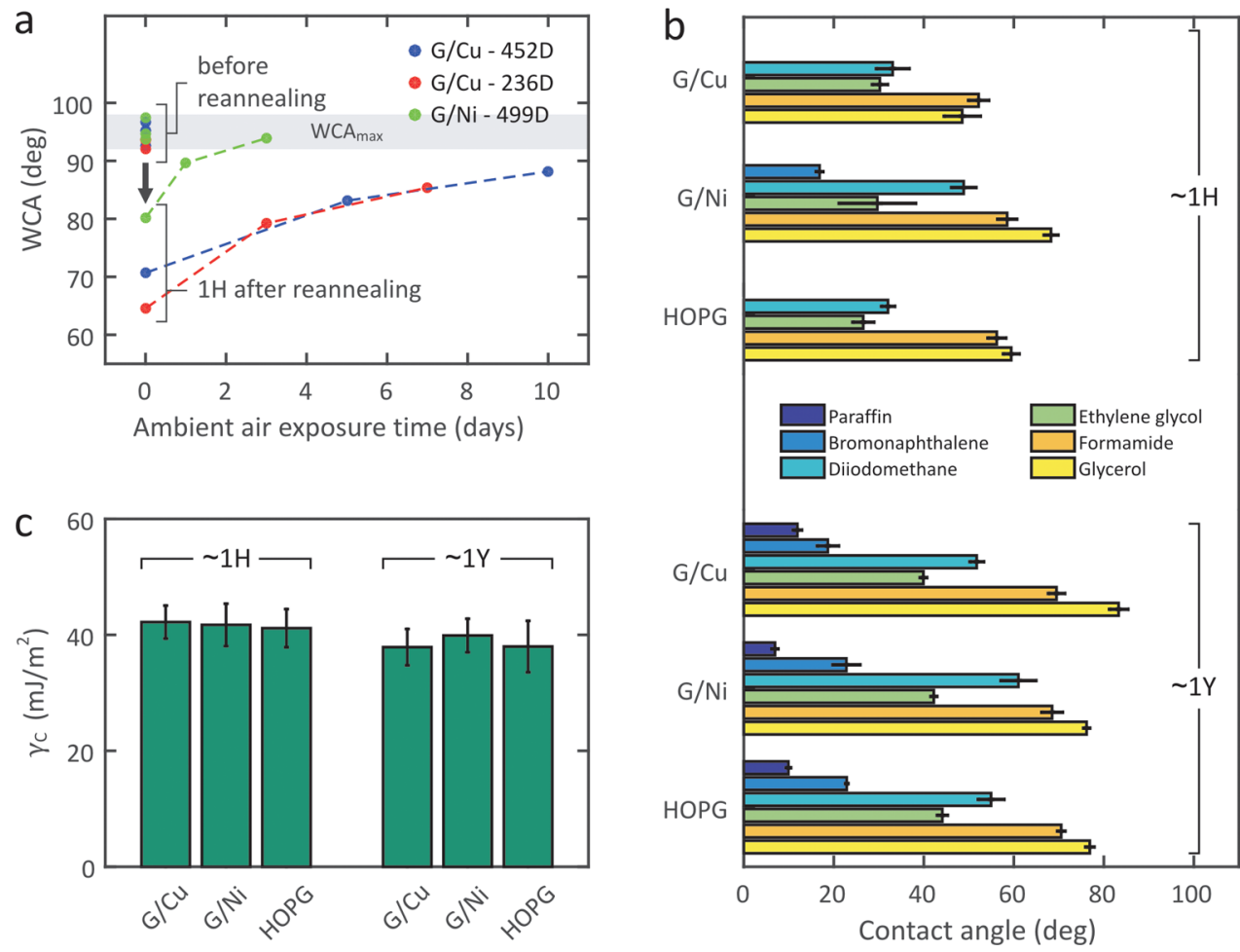

Figure 4. (a) WCA of $\mathrm{G} / \mathrm{Cu}$ and $\mathrm{G} / \mathrm{Ni}$ measured before and after reannealing. The black arrow indicates changes in WCA due to reannealing. Before reannealing, the $\mathrm{G} / \mathrm{Cu}$ samples have been exposed to ambient air for 452 days (blue dots) and 236 days (red dots), and for 499 days for the $\mathrm{G} / \mathrm{Ni}$ samples (green dots). WCA measurements were started within $1 \mathrm{~h}$ after reannealing. The measurement uncertainty of $\pm 3^{\circ}$ is represented by the size of each marker. (b) Contact angle of graphene samples and HOPG measured using various liquids including paraffin, bromonaphthalene, diiodomethane, ethylene glycol, formamide, and glycerol. (c) Calculation of Zisman critical surface energy $\left(\gamma_{\mathrm{C}}\right)$ of graphene samples and HOPG. In (b) and (c), all measurements and calculation were performed on two different sets of samples; each had been exposed to ambient air for either $1 \mathrm{~h}$ or 1 year. Error bars in (b) and (c) indicate standard deviation of measurement and standard error of regression, respectively.

occur and hence will have to be taken into account in any detailed analysis.

As stated above, our data indicate that the physisorption of airborne contaminants, mainly in the form of hydrocarbons, dominates the time-dependent changes in the wettability of graphene. ${ }^{12,14,31,43}$ Surface inhomogeneities, either topographical or chemical, and defect sites might act as preferential adsorption sites. ${ }^{44}$ While oxygen and moisture, either molecularly or as surface oxygen functionalities, may also be adsorbed onto the graphene basal plane or at the edges and defect sites, $^{30-34}$ resulting in the increase of graphene polarity, ${ }^{43}$ it is often followed by hydrocarbon adsorption. ${ }^{45,46}$ It has been suggested that the adsorbed contaminants could be desorbed from graphene (or graphite) at a temperature of lower than $500 \mathrm{~K}^{13,31,47,48}$ Our annealing experiments at 250 ${ }^{\circ} \mathrm{C}$ strongly suggest that the contaminants could be mostly removed, resulting in the return of graphene wettability to its original state (Figure 4a). ${ }^{12,43}$ This finding implies that the wettability of supported graphene cannot be taken as constant, but varies with substrate and ambient air exposure time. We show that the WCA increase follows a linear-logarithmic relationship of WCA $\propto \log (t)$, until saturating at $\mathrm{WCA}_{\max }$ (Figure 2a). In previous literature, this $\mathrm{WCA}_{\max }$ has been often reported as the fixed value of the WCA for both CVD and transferred graphene. ${ }^{8-10,49}$ For transferred graphene, polymer residues might significantly affect the CA measurement, making these previously reported values difficult to directly interpret. ${ }^{50}$ Further, many previous reports did not take into account the ambient exposure time, which leads to contradicting arguments about graphene wettability and wetting transparency. ${ }^{8-10}$ Our data show that if wettabilities for samples were compared only after long-term air exposure, misleading interpretations of complete wetting and nonwetting transparency arguments would arise (Figure 2b,c).

The slope of WCA vs $\log (t)$ in Figure 2a may change depending on the specific ambient conditions, such as humidity, temperature, and pressure. However, all possible variations in ambient conditions are inherently integrated in the data as our long-term study averages a range of local environmental conditions over a period of more than 12 months. In addition, the reference values from previous literature, obtained under different ambient conditions, appear to follow the same trend as our WCA data. The linearlogarithmic relationship itself resembles the Elovichian kinetics that has been satisfactorily applied to model the slow adsorption of gas on solid carbon and other heterogeneous surfaces. ${ }^{51-53}$ Such a kinetic model can be applied here by considering that the first order expansion of surface energy is proportional to WCA and assuming that its change is proportional to the change in surface coverage by adsorbed contaminants. This model implies that the adsorption of contaminants does not stop within the first few hours of ambient air exposure. Instead, it occurs continuously as long as the graphene is still exposed to ambient air, although the adsorption rate changes with time and surface saturation will eventually occur. Nevertheless, further detailed analysis must be performed in order to determine if the adsorption kinetics on the graphene surface is indeed Elovichian, as it suggests that the 

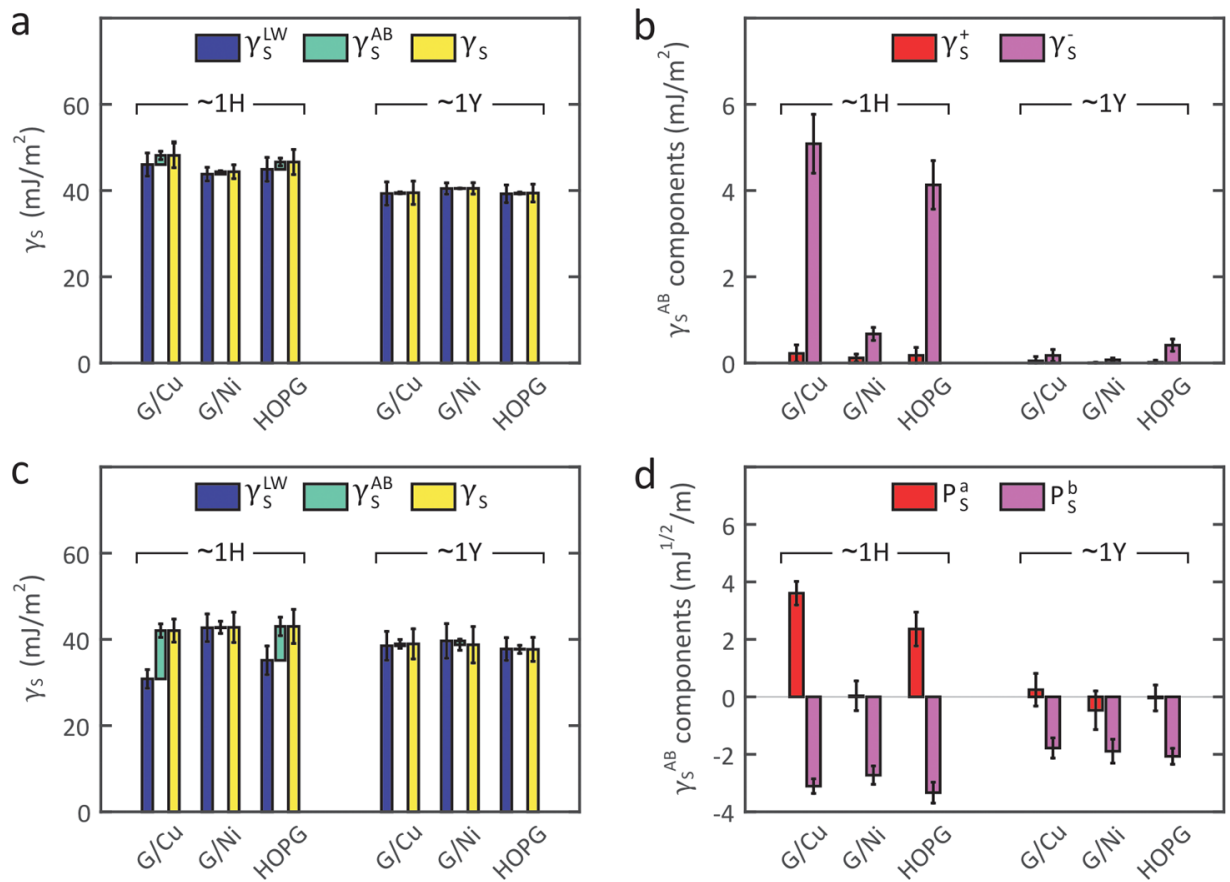

Figure 5. Calculation of total surface free energy $\left(\gamma_{\mathrm{S}}\right)$ of $\mathrm{G} / \mathrm{Cu}, \mathrm{G} / \mathrm{Ni}$, and HOPG (a) and their Lewis acid-base components (b) according to the adjusted van Oss-Chaudury-Good (aOCG) model. Calculation of $\gamma_{\mathrm{S}}$ values of $\mathrm{G} / \mathrm{Cu}, \mathrm{G} / \mathrm{Ni}$, and HOPG (c) and their Lewis acid-base components (d) according to the Chang-Chen (CC) model. All calculations were based on CA data using various liquids (Figure 4b) obtained from two different sets of samples; each had been exposed to ambient air for either $1 \mathrm{~h}$ or 1 year. All error bars indicate the standard error of regression.

adsorption is inhomogeneous and not completely physical. ${ }^{54,55}$ Since the WCA is proportional to the surface coverage by adsorbed contaminants, its value ceases to change when surface saturation is reached. Therefore, it is expected that the measured WCA of graphene changes asymptotically over time from its initial value toward the WCA of the contaminants as the surface is increasingly saturated with contaminants. In this case, $\mathrm{WCA}_{\max }$ represents the WCA of the accumulated contaminants rather than the WCA of graphene itself.

It has to be noted that although all freshly grown supported graphene samples and freshly cleaved HOPG are found to be easily wettable, $\mathrm{G} / \mathrm{Ni}$ is found to be initially less wettable than $\mathrm{G} / \mathrm{Cu}$ and HOPG. This motivates us here to analyze the surface free energy components using a range of well-known fitting models. Here we exclude several fitting models, which have been used in previous literature to calculate the free surface energy of graphene, ${ }^{56}$ due to their obsolescence (see Supporting Information, section 4). ${ }^{57}$ The calculated total surface free energy $\left(\gamma_{S}\right)$ of graphene and HOPG using an adjusted van Oss-Chaudhury-Good (aOCG) model, along with its Lifshitz-van der Waals $\left(\gamma_{S}{ }^{\mathrm{LW}}\right)$ and Lewis acid-base $\left(\gamma_{\mathrm{S}}^{\mathrm{AB}}\right)$ components, are summarized in Figure 5a (see also Supporting Information, Figure S12). The decomposition of acidic $\left(\gamma_{S}{ }^{+}\right)$and basic $\left(\gamma_{S}{ }^{-}\right)$components of $\gamma_{S}^{A B}$ are shown in Figure $5 \mathrm{~b}$. For $t=1 \mathrm{~h}$, the fitted values of $\gamma_{\mathrm{S}}$ of $\mathrm{G} / \mathrm{Cu}$ and $\mathrm{G} / \mathrm{Ni}$ are calculated at $\sim 48$ and $\sim 44 \mathrm{~mJ} / \mathrm{m}^{2}$, respectively, while that of HOPG is $\sim 46.5 \mathrm{~mJ} / \mathrm{m}^{2}$. Furthermore, $\gamma_{\mathrm{S}}^{\mathrm{LW}}$ values of $\mathrm{G} / \mathrm{Cu}$, $\mathrm{G} / \mathrm{Ni}$, and HOPG are approximated at $\sim 46, \sim 43$, and $\sim 45$ $\mathrm{mJ} / \mathrm{m}^{2}$, respectively, or about $96-98 \%$ of their total $\gamma_{\mathrm{S}}{ }^{+}$values. Further decomposition of $\gamma_{\mathrm{S}}^{\mathrm{AB}}$ shows that for $t=1 \mathrm{~h} \mathrm{G} / \mathrm{Cu}$ and HOPG are monopolar basic, with basic component $\gamma_{\mathrm{S}}{ }^{-}$values of $\sim 5$ and $\sim 4 \mathrm{~mJ} / \mathrm{m}^{2}$ respectively and negligible acidic component $\gamma_{S}{ }^{+}$. Although for $t=1 \mathrm{~h} \mathrm{G} / \mathrm{Ni}$ could still be considered monopolar basic, its $\gamma_{\mathrm{S}}{ }^{-}$is only $\sim 0.6 \mathrm{~mJ} / \mathrm{m}^{2}$, implying that it is much less basic than both $\mathrm{G} / \mathrm{Cu}$ and HOPG. For $t=1$ year, the fitted value of $\gamma_{\mathrm{S}}$ of all graphene and HOPG samples decreases to around $39-40 \mathrm{~mJ} / \mathrm{m}^{2}$ and the $\gamma_{\mathrm{S}}{ }^{\mathrm{LW}}$ component accounts for almost $100 \%$ of their total $\gamma_{S}$ values. Indeed, further decomposition of $\gamma_{\mathrm{S}}^{\mathrm{AB}}$ shows that for $t=1$ year $\mathrm{G} / \mathrm{Cu}, \mathrm{G} / \mathrm{Ni}$, and HOPG are almost completely nonpolar.

Values of the calculated total surface free energy $\left(\gamma_{S}\right)$ of graphene and HOPG using the Chang-Chen (CC) model, along with its Lifshitz-van der Waals $\left(\gamma_{S}{ }^{\mathrm{LW}}\right)$ and Lewis acidbase $\left(\gamma_{\mathrm{S}}^{\mathrm{AB}}\right)$ components, are summarized in Figure $5 \mathrm{c}$ (see also Supporting Information, Figure S13). The decomposition of acidic $\left(P_{S}{ }^{\mathrm{a}}\right)$ and basic $\left(P_{\mathrm{S}}^{\mathrm{b}}\right)$ components of $\gamma_{\mathrm{S}}{ }^{\mathrm{AB}}$ are shown in Figure $5 \mathrm{~d}$. For $t=1 \mathrm{~h}$, the fitted value of $\gamma_{\mathrm{S}}$ of $\mathrm{G} / \mathrm{Cu}, \mathrm{G} / \mathrm{Ni}$, and HOPG is calculated at $42-43 \mathrm{~mJ} / \mathrm{m}^{2}$. While $\gamma_{\mathrm{S}}$ values of all graphene and HOPG samples are relatively similar, their $\gamma_{S}{ }^{\mathrm{LW}}$ and $\gamma_{\mathrm{S}}{ }^{\mathrm{AB}}$ components are significantly different. The $\gamma_{\mathrm{S}}{ }^{\mathrm{LW}}$ values of $\mathrm{G} / \mathrm{Cu}$ and HOPG are approximated at 31 and $35 \mathrm{~mJ} / \mathrm{m}^{2}$, respectively, which accounts for about 73 and $81 \%$ of their total $\gamma_{\mathrm{S}}$ values. In contrast, $\gamma_{\mathrm{S}}{ }^{\mathrm{LW}}$ of $\mathrm{G} / \mathrm{Ni}$ is approximated at $43 \mathrm{~mJ} /$ $\mathrm{m}^{2}$, which is $\sim 100 \%$ of its total $\gamma_{S}$ value. Further decomposition of $\gamma_{\mathrm{S}}^{\mathrm{AB}}$ shows that for $t=1 \mathrm{~h} \mathrm{G} / \mathrm{Cu}$ and HOPG are essentially amphoteric, although $\mathrm{G} / \mathrm{Cu}$ is slightly more acidic and HOPG is slightly more basic. On the other hand, for $t=1 \mathrm{~h} \mathrm{G} / \mathrm{Ni}$ is considered monopolar basic, with basic component $P_{\mathrm{S}}^{\mathrm{b}}$ of $\sim-$ $2.7 \mathrm{~mJ}^{1 / 2} / \mathrm{m}$ and negligible acidic component $P_{\mathrm{S}}{ }^{\mathrm{a}}$. For $t=1$ year, $\gamma_{\mathrm{S}}$ of all graphene and HOPG samples decreases to around 37-39 $\mathrm{mJ} / \mathrm{m}^{2}$ and the $\gamma_{\mathrm{S}}{ }^{\mathrm{LW}}$ component accounts for almost $100 \%$ of their total $\gamma_{\mathrm{S}}$ values. Further decomposition of $\gamma_{\mathrm{S}}{ }^{\mathrm{AB}}$ shows that for $t=1$ year $\mathrm{G} / \mathrm{Cu}, \mathrm{G} / \mathrm{Ni}$, and HOPG are weak monopolar basic with a relatively weak basic component $P_{\mathrm{S}}{ }^{\mathrm{b}}$ of -1.7 to $2 \mathrm{~mJ}^{1 / 2} / \mathrm{m}$ and negligible acidic component $P_{\mathrm{S}}{ }^{\mathrm{a}}$. 
According to the aOCG model, the total surface free energies and the Lifshitz-van der Waals components of $\mathrm{G} / \mathrm{Cu}, \mathrm{G} / \mathrm{Ni}$, and HOPG are comparable (Figure 5a). However, the Lewis acid-base component of $\mathrm{G} / \mathrm{Ni}$, in particular its basic component, is considerably weaker than those of $\mathrm{G} / \mathrm{Cu}$ and HOPG (Figure $5 \mathrm{~b}$ ). The relatively strong basic components of $\mathrm{G} / \mathrm{Cu}$ and HOPG allow them to form a strong acid-base interaction with water, rendering them hydrophilic (see also Supporting Information, section 3 and Figure S4). In contrast, the basic component of $\mathrm{G} / \mathrm{Ni}$ is relatively weak, which results in a weak acid-base interaction with water, i.e. less hydrophilic behavior. Note that, in the aOCG model, water is considered more acidic than it is basic; i.e. it bonds to other molecules by accepting electrons rather than donating. According to the CC model, the difference between $\mathrm{G} / \mathrm{Ni}$ and $\mathrm{G} / \mathrm{Cu}$ is not only in their Lewis acid-base components, but also in their Lifshitzvan der Waals components (Figure 5c). The Lifshitz-van der Waals component of $\mathrm{G} / \mathrm{Ni}$ is about 1.4 times higher than that of $\mathrm{G} / \mathrm{Cu}$. On the other hand, the Lewis acid-base component of $\mathrm{G} / \mathrm{Ni}$ is negligible compared to that of $\mathrm{G} / \mathrm{Cu}$ (Figure $5 \mathrm{~d}$ ). Further decomposition of the Lewis acid-base component shows that $\mathrm{G} / \mathrm{Cu}$ and HOPG are essentially amphoteric, while $\mathrm{G} / \mathrm{Ni}$ is monopolar basic. Because in the $\mathrm{CC}$ model water is considered more nucleophilic than it is electrophilic, the amphoteric nature of $\mathrm{G} / \mathrm{Cu}$ and HOPG allows them to form a strong acid-base interaction with water, while the lack of acidic characteristic of $\mathrm{G} / \mathrm{Ni}$ renders it less hydrophilic.

Depending on the surface free energy models the data are fitted with, the exposure to ambient air could either slightly increase (CC model) or slightly decrease (aOCG model) the graphene Lifshitz-van der Waals component (Figure 5). However, both models agree that the exposure to ambient air diminishes the graphene Lewis acid-base components almost completely. Note that both fitting models assume that the surface of interest is the outermost boundary of a continuous monolithic solid. It is thus nontrivial to distinguish if the time evolution of graphene surface free energy is originated from actual changes on the graphene surface or from changes in the underlying substrates of graphene due to oxidation effect. However, our data clearly show that the surface free energy of $\mathrm{G} / \mathrm{Ni}$, along with its components, clearly changes with $t$ despite the fact that the $\mathrm{Ni}$ underneath the graphene remains metallic even after $t=1$ year. Our data also show that a similar time dependent behavior occurs in the surface free energies of $\mathrm{G} / \mathrm{Cu}$ and HOPG despite the fact that for $\mathrm{G} / \mathrm{Cu}$ oxygen intercalation and $\mathrm{Cu}$ oxidation take place underneath the graphene. Hence, this indicates that the dominating cause for the changes in the components of graphene surface free energy observed here is that of physisorption of hydrocarbon, which renders the graphene nonpolar and decreases its total surface free energy by $10-16 \%$, i.e. $37-41 \mathrm{~mJ} / \mathrm{m}^{2}$ within 1 year of ambient air exposure. It has to be noted that the Lewis acid-base components of supported graphene and graphite, although weaker than their Lifshitz-van der Waals components, are nonnegligible. This suggests that the classical van der Waals interaction theory alone is not sufficient to describe the wettability of graphene. ${ }^{8,9}$ Therefore, any future theoretical or numerical studies on the graphene wettability will have to account for not only the van der Waals interactions, but also acid-base interactions.

While graphene and graphite (HOPG) are generally known to be highly nonpolar due to their $\mathrm{sp}^{2}$ structures, their mild polarities have been previously suggested. ${ }^{56}$ The electron-rich $\pi$ system of graphene may act as an electron donor for $\pi-\mathrm{H}$ bonding with water. ${ }^{58}$ Graphene defect sites and surface inhomogeneities, either topographical or chemical, may give rise to the variation in electron affinity and work function, which ultimately influences the formation of acid-base interactions with other electrophile or nucleophile molecules. $^{44,59,60}$ As mentioned above, the strength of the acidbasic component of graphene is not always the same. Differences in the strength of the acid-basic component, especially between $\mathrm{Ni}$ supported and $\mathrm{Cu}$ supported graphene, may originate from differences in the strength of interaction between graphene and the underlying substrate. The fact that the acid-basic component of $\mathrm{G} / \mathrm{Ni}$ is much weaker than that of $\mathrm{G} / \mathrm{Cu}$ suggests that the strong interaction between graphene and $\mathrm{Ni}$ suppresses its electron donating (or accepting) capability, while the weak interaction between graphene and $\mathrm{Cu}$ does not. This indicates that the initial wettability of graphene is indeed influenced by the substrate effect, although this may not be in the same sense as the frequently postulated (complete or partial) graphene wetting transparency argument. This argument would imply that the wettability of supported graphene is mainly due to the wettability of its substrate and suggests that stronger interaction between graphene and its substrate results in higher graphene wettability. In contrast, it is shown herein that stronger interaction between graphene and its substrate results in a lower initial graphene wettability, although the exact mechanism is still unclear at this point.

\section{CONCLUSIONS}

In this study, we systematically investigate the wettability of metal-supported CVD graphene as a function of ambient air exposure time using water and various other test liquids. Our data indicate that the wettability of supported graphene cannot be taken as constant, but varies with substrate and ambient air exposure time. Our data highlight the distinctly different oxidation behavior of the metal underneath the graphene and clearly demonstrate that oxidation effects and changes to the underlying $\mathrm{Cu}$ substrates do occur. Nevertheless, our data show that all supported graphene samples gradually lose their wettability in the measured time frame of over a year of ambient air exposure. The fact that WCA can be "reset" by annealing at a relatively low temperature, together with the universal increase rate in the WCA of all supported graphene samples before saturation at a constant value of $92-98^{\circ}$, implies that the dominating cause for the time dependent change in wettability observed here is that of physisorption of airborne contaminants. Failure to account for the ambient air exposure time may otherwise lead to contradicting arguments about graphene wettability and wetting transparency.

Our analysis of the surface free energy components using various fitting models indicates that the Lewis acid-base component of freshly grown $\mathrm{G} / \mathrm{Ni}$ is considerably weaker than that of freshly grown $\mathrm{G} / \mathrm{Cu}$ and freshly cleaved HOPG. Differences in the strength of the Lewis acid-basic component may actually originate from variations in interaction between graphene and the underlying substrate, where the strong interaction between graphene and $\mathrm{Ni}$ suppresses its electron donating or accepting capability while the weak interaction between graphene and $\mathrm{Cu}$ does not. Furthermore, our data indicate that the polar characteristics of supported graphene and HOPG are non-negligible, although weaker than their nonpolar components, suggesting that the classical van der Waals interaction theory alone is not sufficient to describe the 
wettability of graphene. Our data within 1 year of ambient air exposure indicate that physisorption of airborne contaminants renders the supported graphene increasingly nonpolar, which leads to the gradual loss of its wettability, although its total surface free energy decreases only by $10-16 \%$ to about $37-41$ $\mathrm{mJ} / \mathrm{m}^{2}$. Since changes in surface polarity and energy may affect other properties of graphene, the performance of graphene devices may also change over time due to air exposure during storage and usage. While the findings presented herein represent the wettability of supported graphene, they can also be extrapolated to systematically study and rationalize the time dependent wetting behavior of other supported 2D materials for the benefit of many future application areas. Similarly to that of supported graphene, the wetting behavior of other supported $2 \mathrm{D}$ materials may also be affected by changes to their underlying substrate and adsorption of contaminations.

\section{ASSOCIATED CONTENT}

\section{S Supporting Information}

The Supporting Information is available free of charge on the ACS Publications website at DOI: 10.1021/acs.jpcc.5b10492.

Details of the effect of surface inhomogeneity on the wettability of graphene; SEM and AFM images of supported graphene, HOPG, and bare metal substrates; Raman spectra of $\mathrm{G} / \mathrm{Cu}$ and $\mathrm{G} / \mathrm{Ni}$; contact angle goniometry images of static sessile water drops on bare polycrystalline $\mathrm{Cu}$ and $\mathrm{Ni}$; statistical analysis of "nonwetting transparency" and "complete wetting transparency" hypotheses; calculation of water-graphene interaction potential; XPS $\mathrm{Cu} 2 \mathrm{p}$ spectra of $\mathrm{G} / \mathrm{Cu}$ and bare $\mathrm{Cu}$; XPS $\mathrm{O}$ 1s spectra of supported graphene and HOPG; XPS C 1 s and $\mathrm{O}$ 1s spectra of bare $\mathrm{Cu}$ and $\mathrm{Ni}$; calculation of graphene surface free energy (PDF)

\section{AUTHOR INFORMATION}

\section{Corresponding Author}

*E-mail:sh315@cam.ac.uk.

Notes

The authors declare no competing financial interest.

\section{ACKNOWLEDGMENTS}

We acknowledge funding from EPSRC (Grant EP/K016636/1, GRAPHTED) and ERC (Grant 279342, InsituNANO). P.R.K. acknowledges the Lindemann Trust Fellowship. R.S.W. acknowledges a Research Fellowship from St. John's College, Cambridge, and a EU Marie Skłodowska-Curie Individual Fellowship under grant ARTIST (No. 656870) from the European Union's Horizon 2020 research and innovation programme.

\section{REFERENCES}

(1) Batzill, M. The Surface Science of Graphene: Metal Interfaces, CVD Synthesis, Nanoribbons, Chemical Modifications, and Defects. Surf. Sci. Rep. 2012, 67 (3-4), 83-115.

(2) Weatherup, R. S.; Bayer, B. C.; Blume, R.; Baehtz, C.; Kidambi, P. R.; Fouquet, M.; Wirth, C. T.; Schlögl, R.; Hofmann, S. On the Mechanisms of Ni-Catalysed Graphene Chemical Vapour Deposition. ChemPhysChem 2012, 13 (10), 2544-2549.

(3) Kidambi, P. R.; Bayer, B. C.; Blume, R.; Wang, Z.-J.; Baehtz, C.; Weatherup, R. S.; Willinger, M.-G.; Schloegl, R.; Hofmann, S. Observing Graphene Grow: Catalyst-Graphene Interactions during Scalable Graphene Growth on Polycrystalline Copper. Nano Lett. 2013, 13 (10), 4769-4778.
(4) Yazyev, O. V.; Chen, Y. P. Polycrystalline Graphene and Other Two-Dimensional Materials. Nat. Nanotechnol. 2014, 9 (10), 755767.

(5) Fiori, G.; Bonaccorso, F.; Iannaccone, G.; Palacios, T.; Neumaier, D.; Seabaugh, A.; Banerjee, S. K.; Colombo, L. Electronics Based on Two-Dimensional Materials. Nat. Nanotechnol. 2014, 9 (10), 768779.

(6) Henderson, M. The Interaction of Water with Solid Surfaces: Fundamental Aspects Revisited. Surf. Sci. Rep. 2002, 46 (1-8), 1-308.

(7) Hodgson, A.; Haq, S. Water Adsorption and the Wetting of Metal Surfaces. Surf. Sci. Rep. 2009, 64 (9), 381-451.

(8) Rafiee, J.; Mi, X.; Gullapalli, H.; Thomas, A. V.; Yavari, F.; Shi, Y.; Ajayan, P. M.; Koratkar, N. A. Wetting Transparency of Graphene. Nat. Mater. 2012, 11 (3), 217-222.

(9) Shih, C.-J.; Wang, Q. H.; Lin, S.; Park, K.-C.; Jin, Z.; Strano, M. S.; Blankschtein, D. Breakdown in the Wetting Transparency of Graphene. Phys. Rev. Lett. 2012, 109 (17), 176101.

(10) Raj, R.; Maroo, S. C.; Wang, E. N. Wettability of Graphene. Nano Lett. 2013, 13 (4), 1509-1515.

(11) $\mathrm{Xu}, \mathrm{K}$; Heath, J. R. Wetting: Contact with What? Nat. Mater. 2013, $12(10), 872-873$.

(12) Kozbial, A.; Li, Z.; Sun, J.; Gong, X.; Zhou, F.; Wang, Y.; Xu, H.; Liu, H.; Li, L. Understanding the Intrinsic Water Wettability of Graphite. Carbon 2014, 74, 218-225.

(13) Amadei, C. A.; Lai, C.-Y.; Heskes, D.; Chiesa, M. Time Dependent Wettability of Graphite upon Ambient Exposure: The Role of Water Adsorption. J. Chem. Phys. 2014, 141 (8), 084709.

(14) Li, Z.; Wang, Y.; Kozbial, A.; Shenoy, G.; Zhou, F.; McGinley, R.; Ireland, P.; Morganstein, B.; Kunkel, A.; Surwade, S. P.; et al. Effect of Airborne Contaminants on the Wettability of Supported Graphene and Graphite. Nat. Mater. 2013, 12 (10), 925-931.

(15) Lai, C.-Y.; Tang, T.-C.; Amadei, C. A.; Marsden, A. J.; Verdaguer, A.; Wilson, N.; Chiesa, M. A Nanoscopic Approach to Studying Evolution in Graphene Wettability. Carbon 2014, 80, 784792.

(16) Kidambi, P. R.; Blume, R.; Kling, J.; Wagner, J. B.; Baehtz, C.; Weatherup, R. S.; Schloegl, R.; Bayer, B. C.; Hofmann, S. In Situ Observations during Chemical Vapor Deposition of Hexagonal Boron Nitride on Polycrystalline Copper. Chem. Mater. 2014, 26 (22), 63806392.

(17) Kidambi, P. R.; Ducati, C.; Dlubak, B.; Gardiner, D.; Weatherup, R. S.; Martin, M.-B.; Seneor, P.; Coles, H.; Hofmann, S. The Parameter Space of Graphene Chemical Vapor Deposition on Polycrystalline Cu. J. Phys. Chem. C 2012, 116 (42), 22492-22501.

(18) Weatherup, R. S.; Dlubak, B.; Hofmann, S. Kinetic Control of Catalytic CVD for High-Quality Graphene at Low Temperatures. ACS Nano 2012, 6 (11), 9996-10003.

(19) Weatherup, R. S.; Bayer, B. C.; Blume, R.; Ducati, C.; Baehtz, C.; Schlögl, R.; Hofmann, S. In Situ Characterization of Alloy Catalysts for Low-Temperature Graphene Growth. Nano Lett. 2011, 11 (10), 4154-4160.

(20) Aria, A. I.; Gharib, M. Reversible Tuning of the Wettability of Carbon Nanotube Arrays: The Effect of Ultraviolet/Ozone and Vacuum Pyrolysis Treatments. Langmuir 2011, 27 (14), 9005-9011.

(21) Aria, A. I.; Gharib, M. Physicochemical Characteristics and Droplet Impact Dynamics of Superhydrophobic Carbon Nanotube Arrays. Langmuir 2014, 30 (23), 6780-6790.

(22) Stalder, A.; Kulik, G.; Sage, D.; Barbieri, L.; Hoffmann, P. A Snake-Based Approach to Accurate Determination of Both Contact Points and Contact Angles. Colloids Surf., A 2006, 286 (1-3), 92-103.

(23) Zisman, W. A. Relation of Equilibrium Contact Angle to Liquid and Solid Constitution. In Contact Angle, Wettability, and Adhesion; Fowkes, F. M., Ed.; Advances in Chemistry 43; American Chemical Society: Washington, DC, 1964; pp 1-51.

(24) Van Oss, C. J.; Chaudhury, M. K.; Good, R. J. Interfacial Lifshitz-van Der Waals and Polar Interactions in Macroscopic Systems. Chem. Rev. 1988, 88 (6), 927-941. 
(25) Volpe, C. D.; Siboni, S. Some Reflections on Acid-Base Solid Surface Free Energy Theories. J. Colloid Interface Sci. 1997, 195 (1), 121-136.

(26) Chang, W. V.; Qin, X. Repulsive Acid-Base Interactions: Fantasy or Reality? In Acid-Base Interactions: Relevance to Adhesion Science and Technology; Mittal, K. L., Ed.; VSP: Utrecht, The Netherlands, 2000; pp 3-54.

(27) Chen, F.; Chang, W. V. Applicability Study of a New Acid Base Interaction Model in Polypeptides and Polyamides. Langmuir 1991, 7 (10), 2401-2404.

(28) Blume, R.; Kidambi, P. R.; Bayer, B. C.; Weatherup, R. S.; Wang, Z.-J.; Weinberg, G.; Willinger, M.-G.; Greiner, M.; Hofmann, S.; Knop-Gericke, A.; et al. The Influence of Intercalated Oxygen on the Properties of Graphene on Polycrystalline $\mathrm{Cu}$ under Various Environmental Conditions. Phys. Chem. Chem. Phys. 2014, 16 (47), 25989-26003.

(29) Weatherup, R. S.; Amara, H.; Blume, R.; Dlubak, B.; Bayer, B. C.; Diarra, M.; Bahri, M.; Cabrero-Vilatela, A.; Caneva, S.; Kidambi, P. R.; et al. Interdependency of Subsurface Carbon Distribution and Graphene-Catalyst Interaction. J. Am. Chem. Soc. 2014, 136 (39), 13698-13708.

(30) Yang, Y.; Murali, R. Binding Mechanisms of Molecular Oxygen and Moisture to Graphene. Appl. Phys. Lett. 2011, 98 (9), 093116.

(31) Martinez-Martin, D.; Longuinhos, R.; Izquierdo, J. G.; Marele, A.; Alexandre, S. S.; Jaafar, M.; Gómez-Rodríguez, J. M.; Bañares, L.; Soler, J. M.; Gomez-Herrero, J. Atmospheric Contaminants on Graphitic Surfaces. Carbon 2013, 61, 33-39.

(32) Mitoma, N.; Nouchi, R.; Tanigaki, K. Photo-Oxidation of Graphene in the Presence of Water. J. Phys. Chem. C 2013, 117 (3), $1453-1456$.

(33) Ryu, S.; Liu, L.; Berciaud, S.; Yu, Y.-J.; Liu, H.; Kim, P.; Flynn, G. W.; Brus, L. E. Atmospheric Oxygen Binding and Hole Doping in Deformed Graphene on a $\mathrm{SiO}_{2}$ Substrate. Nano Lett. 2010, 10 (12), 4944-4951.

(34) Cao, P.; Xu, K.; Varghese, J. O.; Heath, J. R. The Microscopic Structure of Adsorbed Water on Hydrophobic Surfaces under Ambient Conditions. Nano Lett. 2011, 11 (12), 5581-5586.

(35) Biesinger, M. C.; Lau, L. W. M.; Gerson, A. R.; Smart, R. S. C. Resolving Surface Chemical States in XPS Analysis of First Row Transition Metals, Oxides and Hydroxides: Sc, Ti, V, Cu and Zn. Appl. Surf. Sci. 2010, 257 (3), 887-898.

(36) Zhou, F.; Li, Z.; Shenoy, G. J.; Li, L.; Liu, H. Enhanced RoomTemperature Corrosion of Copper in the Presence of Graphene. ACS Nano 2013, 7 (8), 6939-6947.

(37) Schriver, M.; Regan, W.; Gannett, W. J.; Zaniewski, A. M.; Crommie, M. F.; Zettl, A. Graphene as a Long-Term Metal Oxidation Barrier: Worse than Nothing. ACS Nano 2013, 7 (7), 5763-5768.

(38) Patera, L. L.; Africh, C.; Weatherup, R. S.; Blume, R.; Bhardwaj, S.; Castellarin-Cudia, C.; Knop-Gericke, A.; Schloegl, R.; Comelli, G.; Hofmann, S.; et al. In Situ Observations of the Atomistic Mechanisms of Ni Catalyzed Low Temperature Graphene Growth. ACS Nano 2013, 7 (9), 7901-7912.

(39) Weatherup, R. S.; D’Arsié, L.; Cabrero-Vilatela, A.; Caneva, S.; Blume, R.; Robertson, J.; Schlögl, R.; Hofmann, S. Long-Term Passivation of Strongly Interacting Metals with Single-Layer Graphene. J. Am. Chem. Soc. 2015, 137 (45), 14358-14366.

(40) Martin, M.-B.; Dlubak, B.; Weatherup, R. S.; Piquemal-Banci, M.; Yang, H.; Blume, R.; Schloegl, R.; Collin, S.; Petroff, F.; Hofmann, S.; et al. Protecting Nickel with Graphene Spin-Filtering Membranes: A Single Layer Is Enough. Appl. Phys. Lett. 2015, 107 (1), 012408.

(41) Biesinger, M. C.; Payne, B. P.; Lau, L. W. M.; Gerson, A.; Smart, R. S. C. X-Ray Photoelectron Spectroscopic Chemical State Quantification of Mixed Nickel Metal, Oxide and Hydroxide Systems. Surf. Interface Anal. 2009, 41 (4), 324-332.

(42) Trevoy, D. J.; Johnson, H. The Water Wettability of Metal Surfaces. J. Phys. Chem. 1958, 62 (7), 833-837.

(43) Ashraf, A.; Wu, Y.; Wang, M. C.; Aluru, N. R.; Dastgheib, S. A.; Nam, S. Spectroscopic Investigation of the Wettability of Multilayer
Graphene Using Highly Ordered Pyrolytic Graphite as a Model Material. Langmuir 2014, 30 (43), 12827-12836.

(44) Lazar, P.; Karlický, F.; Jurečka, P.; Kocman, M.; Otyepková, E.; Śafárová, K.; Otyepka, M. Adsorption of Small Organic Molecules on Graphene. J. Am. Chem. Soc. 2013, 135 (16), 6372-6377.

(45) Chiba, K.; Ohmori, R.; Tanigawa, H.; Yoneoka, T.; Tanaka, S. H2O Trapping on Various Materials Studied by AFM and XPS. Fusion Eng. Des. 2000, 49-50, 791-797.

(46) Wang, R.; Kido, M. Analysis of Air Adsorptive on Solid Surfaces by AFM and XPS. Trans. Nonferrous Met. Soc. China 2006, 16, s753s758.

(47) Aria, A. I.; Gani, A. W.; Gharib, M. Effect of Dry Oxidation on the Energy Gap and Chemical Composition of CVD Graphene on Nickel. Appl. Surf. Sci. 2014, 293, 1-11.

(48) Zacharia, R.; Ulbricht, H.; Hertel, T. Interlayer Cohesive Energy of Graphite from Thermal Desorption of Polyaromatic Hydrocarbons. Phys. Rev. B: Condens. Matter Mater. Phys. 2004, 69 (15), 155406.

(49) Preston, D. J.; Mafra, D. L.; Miljkovic, N.; Kong, J.; Wang, E. N. Scalable Graphene Coatings for Enhanced Condensation Heat Transfer. Nano Lett. 2015, 15 (5), 2902-2909.

(50) Kratzer, M.; Bayer, B. C.; Kidambi, P. R.; Matković, A.; Gajić, R.; Cabrero-Vilatela, A.; Weatherup, R. S.; Hofmann, S.; Teichert, C. Effects of Polymethylmethacrylate-Transfer Residues on the Growth of Organic Semiconductor Molecules on Chemical Vapor Deposited Graphene. Appl. Phys. Lett. 2015, 106 (10), 103101.

(51) Zaïdi, H.; Paulmier, D.; Lepage, J. The Influence of the Environment on the Friction and Wear of Graphitic Carbons. Appl. Surf. Sci. 1990, 44 (3), 221-233.

(52) Heimberg, J. A.; Wahl, K. J.; Singer, I. L.; Erdemir, A. Superlow Friction Behavior of Diamond-like Carbon Coatings: Time and Speed Effects. Appl. Phys. Lett. 2001, 78 (17), 2449.

(53) Rudzinski, W.; Panczyk, T. Kinetics of Isothermal Adsorption on Energetically Heterogeneous Solid Surfaces: A New Theoretical Description Based on the Statistical Rate Theory of Interfacial Transport. J. Phys. Chem. B 2000, 104 (39), 9149-9162.

(54) Low, M. J. D. Kinetics of Chemisorption of Gases on Solids. Chem. Rev. 1960, 60 (3), 267-312.

(55) Brunauer, S.; Emmett, P. H.; Teller, E. Adsorption of Gases in Multimolecular Layers. J. Am. Chem. Soc. 1938, 60 (2), 309-319.

(56) Kozbial, A.; Li, Z.; Conaway, C.; McGinley, R.; Dhingra, S.; Vahdat, V.; Zhou, F.; D'Urso, B.; Liu, H.; Li, L. Study on the Surface Energy of Graphene by Contact Angle Measurements. Langmuir 2014, 30 (28), 8598-8606.

(57) Etzler, F. M. Determination of the Surface Free Energy of Solids. Rev. Adhes. Adhes. 2013, 1 (1), 3-45.

(58) Suzuki, S.; Green, P. G.; Bumgarner, R. E.; Dasgupta, S.; Goddard, W. A.; Blake, G. A. Benzene Forms Hydrogen Bonds with Water. Science 1992, 257 (5072), 942-945.

(59) Zhou, H.; Ganesh, P.; Presser, V.; Wander, M. C. F.; Fenter, P.; Kent, P. R. C.; Jiang, D.; Chialvo, A. A.; McDonough, J.; Shuford, K. L.; et al. Understanding Controls on Interfacial Wetting at Epitaxial Graphene: Experiment and Theory. Phys. Rev. B: Condens. Matter Mater. Phys. 2012, 85 (3), 035406.

(60) Munz, M.; Giusca, C. E.; Myers-Ward, R. L.; Gaskill, D. K.; Kazakova, O. Thickness-Dependent Hydrophobicity of Epitaxial Graphene. ACS Nano 2015, 9, 8401-8411. 